Pacific Journal of Mathematics

A GENERALIZATION OF AN INEQUALITY DUE TO 


\title{
A GENERALIZATION OF AN INEQUALITY DUE TO BEURLING
}

\author{
ARTHUR E. LIVINGSTON
}

1. Introduction. In 1941, Arne Beurling gave a proof (unpublished) of the following result:

$$
\begin{aligned}
& \text { If } a_{n} \geq 0, b_{n} \geq 0 \text { for } n=1,2, \cdots \text {, and } \\
& \qquad \sum_{m=1}^{\infty} m a_{m}^{2}<\infty, \sum_{n=1}^{\infty} n b_{n}^{2}<\infty,
\end{aligned}
$$

then

$$
\sum_{m=1}^{\infty} \sum_{n=1}^{\infty} a_{m} b_{n} / \log (m+n) \leq K\left(\sum_{m=1}^{\infty} m a_{m}^{2}\right)^{1 / 2}\left(\sum_{n=1}^{\infty} n b_{n}^{2}\right)^{1 / 2}
$$

with $0<K<4 e$.

If we set

$$
\alpha(x)=\int_{1}^{x} t^{-1} d t,
$$

then the inequality ( 1 ) is of the form

$$
\sum_{m=1}^{\infty} \sum_{n=1}^{\infty} a_{m} b_{n} / u_{i}(m+n) \leq K(\alpha)\left[\sum_{m=1}^{\infty} a_{m}^{2} / \alpha^{\prime}(m)\right]^{1 / 2}\left[\sum_{n=1}^{\infty} b_{n}^{2} / \alpha^{\prime}(n)\right]^{1 / 2},
$$

and it is the purpose of this note to generalize this latter inequality. As an example of the type of result to be obtained, we quote the integral analogue of (2):

THEOREM 1. Let $\alpha(x)$ be nonnegative, nondecreasing, and locally absolutely continuous on the interval $0 \leq x<\infty$. If $F(x) \geq 0, G(x) \geq 0$ for $0 \leq x<\infty$, and

Received April 10, 1953. The author is a National Science Foundation Fellow.

Pacific J. Math. 4 (1954), 251-257 


$$
\int_{0}^{\infty} \frac{[F(x)]^{p}}{\left[\alpha^{\prime}(x)\right]^{p-1}} d x<\infty, \int_{0}^{\infty} \frac{[G(y)]^{q}}{\left[\alpha^{\prime}(y)\right]^{q-1}} d y<\infty
$$

where $1<p<\infty$ and $p^{-1}+q^{-1}=1$, then

$$
\begin{aligned}
& \int_{0}^{\infty} \int_{0}^{\infty} \frac{F(x) G(y)}{\alpha(x+y)} d x d y \\
& \quad \leq K(\alpha)\left\{\int_{0}^{\infty} \frac{[F(x)]^{p}}{\left[\alpha^{\prime}(x)\right]^{p-1}} d x\right\}^{1 / p}\left\{\int_{0}^{\infty} \frac{[G(y)]^{q}}{\left[\alpha^{\prime}(y)\right]^{q-1}} d y\right\}^{1 / p}
\end{aligned}
$$

with $0<K(\alpha) \leq p+q$.

If $\alpha(x+y) \geq \alpha(x)+\alpha(y)$, then $K(\alpha) \leq \pi / \sin (\pi / p)$. If $\alpha(0)=0$, $\alpha(x) \rightarrow \infty$ as $x \rightarrow \infty$, and $\alpha(x+y) \leq \alpha(x)+\alpha(y)$, then $K(\alpha) \geq$ $\pi / \sin (\pi / p)$.

The author wishes to acknowledge that any novelty in the subject matter of this note is due entirely to Professor Beurling who suggested the very general Theorem 2 below.

2. The main result. This is:

ТнЕовем 2. Let $\alpha(x)$ be nonnegative, nondecreasing, and continuous from the right for $0 \leq x<\infty$. Let $f(x) \geq 0, g(x) \geq 0$ for $0 \leq x<\infty$. Let $1<p<\infty$ and $p^{-1}+q^{-1}=1$. If

$$
\int_{0}^{\infty}[f(x)]^{p} d \alpha(x)<\infty, \int_{0}^{\infty}[g(y)]^{q} d \alpha(y)<\infty,
$$

then

(4) $\int_{0}^{\infty} \int_{0}^{\infty} \frac{f(x) g(y)}{\alpha(x+y)} d \alpha(x) d \alpha(y)$

$$
\leq K(\alpha)\left\{\int_{0}^{\infty}[f(x)]^{p} d \alpha(x)\right\}^{1 / p}\left\{\int_{0}^{\infty}[g(y)]^{q} d \alpha(y)\right\}^{1 / q}
$$

with $0<K(\alpha) \leq p+q$. 
If $\alpha(x+y) \geq \alpha(x)+\alpha(y)$, then

(5)

$$
K(\alpha) \leq \pi / \sin (\pi / p)
$$

If $\alpha(0)=0, \alpha(x) \rightarrow \infty$ as $x \rightarrow \infty, \alpha(x)$ is continuous for $0 \leq x<\infty$, and $\alpha(x+y) \leq \alpha(x)+\alpha(y)$, then

$$
K(\alpha) \geq \pi / \sin (\pi / p)
$$

Proof. We have

$$
\begin{aligned}
I & =\int_{0}^{\infty} \int_{0}^{\infty} \frac{f(x) g(y)}{\alpha(x+y)} d \alpha(x) d \alpha(y) \\
& =\int_{0}^{\infty} \int_{0}^{\infty} \frac{f(x) g(y)}{\alpha(x+y)}[\alpha(x) / \alpha(y)]^{1 / p q}[\alpha(y) / \alpha(x)]^{1 / p q} d \alpha(x) d \alpha(y) \\
& \leq P^{1 / p} Q^{1 / q} .
\end{aligned}
$$

by Hölder's Inequality $[1$, p. 11], where

$$
\begin{aligned}
& P=\int_{0}^{\infty} \int_{0}^{\infty} \frac{[f(x)]^{p}}{\alpha(x+y)}[\alpha(x) / \alpha(y)]^{1 / q} d \alpha(x) d \alpha(y), \\
& Q=\int_{0}^{\infty} \int_{0}^{\infty} \frac{[g(y)]^{q}}{\alpha(x+y)}[\alpha(y) / \alpha(x)]^{1 / p} d \alpha(x) d \alpha(y) .
\end{aligned}
$$

Since $\alpha(x)$ is nondecreasing, we have

$$
\alpha(x+y) \geq \max [\alpha(x), \alpha(y)]
$$

Consequently,

$$
\begin{aligned}
J & =\int_{0}^{\infty} \frac{[\alpha(x) / \alpha(y)]^{1 / q}}{\alpha(x+y)} d \alpha(y) \leq \int_{0}^{\infty} \frac{[\alpha(x) / \alpha(y)]^{1 / q}}{\max [\alpha(x), \alpha(y)]} d \alpha(y) \\
& =[\alpha(x)]^{-1 / p} \int_{0}^{x}[\alpha(y)]^{-1 / q} d \alpha(y)+[\alpha(x)]^{1 / q} \int_{x}^{\infty}[\alpha(y)]^{-1-1 / q} d \alpha(y) \\
& \leq p\left\{1-[\alpha(0) / \alpha(x)]^{1 / p}\right\}+q\left\{1-[\alpha(x) / \alpha(\infty)]^{1 / q}\right\} \leq p+q .
\end{aligned}
$$


In a similar way, we find that

$$
\int_{0}^{\infty} \frac{[\alpha(y) / \alpha(x)]^{1 / p}}{\alpha(x+y)} d \alpha(x) \leq p+q
$$

Thus,

$$
l \leq P^{1 / p} Q^{1 / q} \leq(p+q)\left\{\int_{0}^{\infty}[f(x)]^{p} d \alpha(x)\right\}^{1 / p}\left\{\int_{0}^{\infty}[g(y)] q d c_{1}(y)\right\}^{1 / q},
$$

and this implies (4).

If $\alpha(x+y) \geq \alpha(x)+\alpha(y)$, then we have

$$
\begin{aligned}
& J=\int_{0}^{\infty} \frac{[\alpha(x) / \alpha(y)]^{1 / q}}{\alpha(x+y)} d \alpha(y) \leq \int_{0}^{\infty} \frac{[\alpha(x) / \alpha(y)]^{1 / q}}{\alpha(x)+\alpha(y)} d \alpha(y) \\
& \quad \leq \int_{\alpha(0) / \alpha(x)}^{\alpha(\infty) / \alpha(x)} t^{-1 / q}(1+t)^{-1} d t \leq \int_{0}^{\infty} t^{-1 / q}(1+t)^{-1} d t=\pi / \sin (\pi / p),
\end{aligned}
$$

and this implies (5).

If $\alpha(0)=0, \alpha(\infty)=\infty, \alpha(x)$ is continuous for $0 \leq x<\infty$, and $\alpha(x+y) \leq$ $a(x)+\alpha(y)$, then

$$
I \geq \int_{0}^{\infty} \int_{0}^{\infty} \frac{f(x) g(y)}{\sigma^{(}(x)+\alpha(y)} d \alpha(x) d \alpha(y)=\int_{0}^{\infty} \int_{0}^{\infty} \frac{F(s) G(t)}{s+t} d s d t=I_{1},
$$

where we have made the changes of variable $\alpha(x)=s, \alpha(y)=t$ and set $F(s)=f(x), G(t)=g(y)$. By Hilbert's Inequality [1, 226],

$$
\begin{aligned}
& I_{1} \leq[\pi / \sin (\pi / p)]\left\{\int_{0}^{\infty}[F(s)]^{p} d s\right\}^{1 / p}\left\{\int_{0}^{\infty}[G(t)]^{q} d t\right\}^{1 / q} \\
& =[\pi / \sin (\pi / p)]\left\{\int_{0}^{\infty}[f(x)]^{p} d \alpha(x)\right\}^{1 / p}\left\{\int_{0}^{\infty}[g(y)]^{q} d \alpha(y)\right\}^{1 / q},
\end{aligned}
$$

and the constant $\pi / \sin (\pi / p)$ is the best possible $[1$, p. 226]. This gives (6).

We note that the inequality (4), for $\alpha(x)$ continuous, could be obtained directly from Theorem 319 of [1, p. 229] as follows: 


$$
\begin{aligned}
I & \leq \int_{0}^{\infty} \int_{0}^{\infty} \frac{f(x) g(y)}{\max [\alpha(x), \alpha(y)]} d \alpha(x) d \alpha(y)=\int_{0}^{\infty} \int_{0}^{\infty} \frac{F(s) G(t)}{\max [s, t]} d s d t \\
& \leq k\left\{\int_{0}^{\infty}[F(s)]^{p} d s\right\}^{1 / p}\left\{\int_{0}^{\infty}[G(t)]^{q} d t\right\}^{1 / q} \\
& =k\left\{\int_{0}^{\infty}[f(x)]^{p} d \alpha(x)\right\}^{1 / p}\left\{\int_{0}^{\infty}[g(y)]^{q} d a_{i}(y)\right\}^{1 / q},
\end{aligned}
$$

where

$$
k=\int_{0}^{\infty} \frac{s^{-1 / q} d s}{\max [s, 1]}=p+q
$$

We have made the changes of variable $\alpha(x)=s, \alpha(y)=t$ and set

$$
\begin{aligned}
F(s) & =f(x) & & \text { for } \alpha(0) \leq s \leq a(\infty), \\
& =0 & & \text { otherwise, } \\
G(t) & =g(y) & & \text { for } \alpha(0) \leq t \leq \alpha(\infty), \\
& =0 & & \text { otherwise. }
\end{aligned}
$$

3. Corollaries. If we set $f(x)=F(x) / \alpha^{\prime}(x), g(y)=G(y) / \alpha^{\prime}(y)$ in Theorem 2, we obtain Theorem 1.

As another application of Theorem 2, we deduce:

THEOREM 3. Let the sequence $\left\{\alpha_{n}\right\}_{1}^{\infty}$ be nonnegative and nondecreasing for $n=1,2, \cdots$, and set $\alpha_{0}=0$. Let $1<p<\infty$ and $p^{-1}+q^{-1}=1$. If $a_{n} \geq 0$, $b_{n} \geq 0$ for $n=1,2, \cdots$ and

$$
\sum_{m=1}^{\infty} a_{m}^{p} /\left(\alpha_{m}-\alpha_{m-1}\right)^{p-1}<\propto, \sum_{n=1}^{\infty} b_{n}^{q} /\left(\alpha_{n}-\alpha_{n-1}\right)^{q-1}<\infty,
$$

then

$$
\begin{aligned}
& \sum_{m=1}^{\infty} \sum_{n=1}^{\infty} a_{m} b_{n} / \alpha_{m+n} \\
& \quad \leq K(\alpha)\left\{\sum_{m=1}^{\infty} a_{m}^{p} /\left(\alpha_{m}-\alpha_{m-1}\right)^{p-1}\right\}^{1 / p}\left\{\sum_{n=1}^{\infty} b_{n}^{\left.q /\left(\alpha_{n}-\alpha_{n-1}\right)^{q-1}\right\}^{1 / q} .}\right.
\end{aligned}
$$


with $0<K(\alpha) \leq p+q$.

Proof. Let $a(x), 0 \leq x<\propto$, be the polygonal function with vertices $\left(n, \alpha_{n}\right), n=0,1, \cdots$. Set $f(x)=A_{n} \geq 0, g(x)=B_{n} \geq 0$ for $n-1 \leq x<n$, $n=1,2, \ldots$. By Theorem 2,

$$
\begin{aligned}
\sum_{m=1}^{\infty} \sum_{n=1}^{\infty} A_{m} B_{n} \int_{m l-1}^{m} \int_{n-1}^{n} \frac{d \alpha(x) d \alpha(y)}{\alpha(x+y)} \\
\leq K(\alpha)\left\{\sum_{m=1}^{\infty} A_{m}^{p}\left(\alpha_{m}-\alpha_{m-1}\right)\right\}^{1 / p}\left\{\sum_{n=1}^{\infty} B_{n}^{q}\left(\alpha_{n}-\alpha_{n-1}\right)\right\}^{1 / q},
\end{aligned}
$$

with $0<K(\alpha) \leq p+q$. Since $\alpha(x)$ is nondecreasing, the double sum dominates

$$
\sum_{m=1}^{\infty} \sum_{n=1}^{\infty} \frac{A_{m} B_{n}}{a_{m+n}}\left(\alpha_{m}-\alpha_{m-1}\right)\left(\alpha_{n}-\alpha_{n-1}\right) .
$$

Setting $A_{m}\left(\alpha_{m}-\alpha_{m-1}\right)=a_{m}, B_{m}\left(\alpha_{m}-\alpha_{m-1}\right)=b_{m}$ gives (7).

As a special case of Theorem 3 , we take $\alpha_{0}=0, \alpha_{n}-\alpha_{n-1}=1 / n$ for $n=1,2, \cdots$. Since, for $n=2,3, \cdots$,

$$
\alpha_{n}=\sum_{k=1}^{n} d^{-1}<1+\log n \leq\left(1+\frac{1}{\log 2}\right) \log n,
$$

we find that

$$
\sum_{m=1}^{\infty} \sum_{n=1}^{\infty} a_{m} b_{n} / \log (m+n) \leq M\left(\sum_{m=1}^{\infty} m^{p-1} a_{m}^{p}\right)^{1 / p}\left(\sum_{n=1}^{\infty} n^{q-1} b_{n}^{q}\right)^{1 / q}
$$

with $0<M<(p+q)(1+1 / \log 2)$. For $p=2$, this is the inequality (1) with a slightly smaller bound for the constant.

4. A generalization to several variables. The alternative proof offered for Theorem 2 suggests that the inequalities of this paper can be stated for $N$ variables, $N \geq 2$.

For example, we have: 
THEOREM 2'. Let $\alpha(x)$ be continuous, nonnegative, and nondecreasing for $0 \leq x<\infty$. Let $p_{1}>1, \cdots, p_{N}>1$ and $p_{1}^{-1}+\cdots+p_{N}^{-1}=1$. If $f_{1}(x) \geq 0, \cdots$, $f_{N}(x) \geq 0$ for $0 \leq x<\infty$ and

$$
\int_{0}^{\infty}\left[f_{i}(x)\right]^{p_{i}} d \alpha(x)<\infty
$$

for $i=1, \cdots, N$, then

$$
\int_{0}^{\infty} \cdots \int_{0}^{\infty} \frac{\prod_{i=1}^{N} f_{i}\left(x_{i}\right) d \alpha\left(x_{i}\right)}{\left[\alpha\left(\sum_{i=1}^{N} x_{i}\right)\right]^{N-1}} \leq K_{N}(\alpha) \prod_{i=1}^{N}\left\{\int_{0}^{\infty}\left[f_{i}(x)\right]^{p_{i}} d \alpha(x)\right\}^{1 / p_{i}}
$$

with

$$
0<K_{N}(\alpha) \leq \int_{0}^{\infty} \cdots \int_{0}^{\infty} \frac{\prod_{i=1}^{N-1} x_{i}^{-1 / p_{i}} d x_{i}}{\left\{\max \left[x_{1}, \cdots, x_{N-1}, 1\right]\right\}^{N-1}}
$$

If $\alpha(x+y) \geq \alpha(x)+\alpha(y)$, then

$$
K_{N}(\alpha) \leq \int_{0}^{\infty} \cdots \int_{0}^{\infty} \frac{\prod_{i=1}^{N-1} x_{i}^{-1 / p_{i}} d x_{i}}{\left[1+\sum_{i=1}^{N-1} x_{i}\right]^{N-1}}=M_{N}
$$

If $\alpha(0)=0, \alpha(x) \rightarrow \infty$ as $x \rightarrow \infty$ and $\alpha(x+y) \leq \alpha(x)+\alpha(y)$, then $K_{N}(\alpha) \geq M_{N}$

The proof is patterned on that of Theorem 322 of $[1, p .231]$.

\section{RFERENCE}

1. G. H. Hardy, J.E. Littlewood, and G. Polya, Inequalities, Cambridge, England, 1952.

THE INSTITUTE FOR ADVANCED STUDY 



\section{PACIFIC JOURNAL OF MATHEMATICS}

\section{EDITORS}

\author{
M.M. SCHIFFE R* \\ Stanford University \\ Stanford, California \\ E. HEWITT \\ University of Washington \\ Seattle 5, Washington
}

\author{
R.P. DILWORTH \\ Calif ornia Institute of Technology \\ Pasadena 4, California \\ E. F. BECKENBACH** \\ University of California \\ Los Angeles 24, California
}

\section{ASSOCIATE EDITORS}

$\begin{array}{llll}\text { H. BUSEMANN } & \text { P.R. HALMOS } & \text { BØRGE JESSEN } & \text { J. J. STOKER } \\ \text { HERBERT FEDERER } & \text { HEINZ HOPF } & \text { PAUL LÉVY } & \text { E. G. STRAUS } \\ \text { MARSHALL HALL } & \text { R.D. JAMES } & \text { GEORGE PÓLYA } & \text { KÔSAKU YOSIDA }\end{array}$

\section{SPONSORS}

UNIVERSITY OF BRITISH COLUMBIA

UNIVERSITY OF SOUTHERN CALIFORNIA

CALIFORNIA INSTITUTE OF TECHNOLOGY

UNIVERSITY OF CALIFORNIA, BERKELEY

STANFORD RESEARCH INSTITUTE

UNIVERSITY OF CALIFORNIA, DAVIS

STANFORD UNIVERSITY

UNIVERSITY OF CALIFORNIA, LOS ANGELES

WASHINGTON STATE COLLEGE

UNIVERSITY OF CALIFORNIA, SANTA BARBARA

UNIVERSITY OF WASHINGTON

UNIVERSITY OF NEVADA

OREGON STATE COLLEGE

AMERICAN MATHEMATICAL SOCIETY

UNIVERSITY OF OREGON

HUGHES AIRCRAFT COMPANY

Mathematical papers intended for publication in the Pacific Journal of Mathematics should be typewritten (double spaced), and the author should keep a complete copy. Manuscripts may be sent to any of the editors. Manuscripts intended for the outgoing editors should be sent to their successors. All other communications to the editors should be addressed to the managing editor, E.G. Straus, at the University of California Los Angeles 24, California.

50 reprints of each article are furnished free of charge; additional copies may be obtained at cost in multiples of 50 .

The Pacific Journal of Mathematics is published quarterly, in March, June, September, and December. The price per volume (4 numbers) is $\$ 12.00$; single issues, $\$ 3.50$; back numbers (Volumes $1,2,3$ ) are available at $\$ 2.50$ per copy. Special price to individual faculty members of supporting institutions and to individual members of the American Mathematical Society: $\$ 4.00$ per volume; single issues, $\$ 1.25$.

Subscriptions, orders for back numbers, and changes of address should be sent to the publishers, University of California Press, Berkeley 4, California.

Printed at Ann Arbor, Michigan. Entered as second class matter at the Post Office, Berkeley, California.

* To be succeeded in 1955, by H.L. Royden, Stanford University, Stanford, California.

** To be succeeded in 1955, by E.G. Straus, University of California, Los Angeles 24, Calif.

UNIVERSITY OF CALIFORNIA PRESS - BERKELEY AND LOS ANGELES

COPYRIGHT 1954 BY PACIFIC JOURNAL OF MATHEMATICS 


\section{Pacific Journal of Mathematics}

\section{Vol. 4, No. $2 \quad$ June, 1954}

Henry Ludwig Alder, Generalizations of the Rogers-Ramanujan

identities ........................................ 161

E. M. Beelsey, Concerning total differentiability of functions of class $P$. . . 169

L. Carlitz, The number of solutions of some special equations in a finite

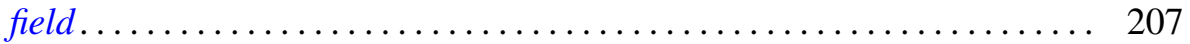

Marshall Hall, On a theorem of Jordan ............................ 219

J. D. Hill, Remarks on the Borel property..................... 227

Joseph Lehner, Note on the Schwarz triangle functions ............... 243

Arthur Eugene Livingston, A generalization of an inequality due to

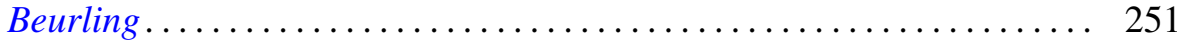

Edgar Reich, An inequality for subordinate analytic functions .......... 259

Dan Robert Scholz, Some minimum problems in the theory of functions ... . 275

J. C. Shepherdson, On two problems of Kurepa ................. 301

Abraham Wald, Congruent imbedding in F-metric spaces ............ 305

Gordon L. Walker, Fermat's theorem for algebras ............... 317 